\title{
Highly Sensitive Electrochemical Determination of Cadmium (II) in Environmental Water Based on the Electrodeposited Bismuth Nanoparticles
}

\author{
Guojing Fan ${ }^{1,2,}$ Dasun Zhai ${ }^{1, *}$ and Dongsheng Zou ${ }^{1 *}$ \\ ${ }^{1}$ Hunan Agricultural University, Changsha, Hunan, 410128, China \\ ${ }^{2}$ School of History - Culture and Tourism GanNan Normal University Ganzhou, Jiangxi, 341000, \\ China \\ *E-mail: dongshengzou2015@163.com
}

doi: $10.20964 / 2016.06 .5$

Received: 27 February 2016 / Accepted: 25 March 2016 / Published: 4 May 2016

\begin{abstract}
Heavy metal ions in environmental water have become an important health threat in human due to their not biodegradable and could accumulate in aquatic organism. In this paper, we demonstrated an electrochemical approach for cadmium ions determination based on the electrodeposited bismuth nanoparticles. The morphology and properties of electrodeposited bismuth nanoparticles were characterized and discussed. The electrochemical determination conditions were optimized and then successfully applied for detecting $\mathrm{Cd}^{2+}$ in tourism scenic area collected hot spring water samples. The results showed the proposed $\mathrm{Cd}(\mathrm{II})$ electrochemical sensor had a high potential for tourism scenic protection application.
\end{abstract}

Keywords: Cadmium; Bismuth; Electrodeposition; Sensor; Tourism scenic protection

\section{FULL TEXT}

(C) 2016 The Authors. Published by ESG (www.electrochemsci.org). This article is an open access article distributed under the terms and conditions of the Creative Commons Attribution license (http://creativecommons.org/licenses/by/4.0/). 